NORMAL ELECTROENCEPHALOGRAMS IN SUBACUTE SCLEROSING PANENCEPHALITIS (SSPE), Michael A. Sisk and John F. Griffith, Duke Univ. Med. Ctr., Dept. of Ped., Durham, N. C.

Eleven cases of SSPE from the mural southeast were studied at Duke from 1968-73. Eight patients had a history of measles immunization and 5 of these reportedly had antecedent natural measles. The diagnosis was confirmed in every case either by the ultrastructural demonstration of virus nucleocapsids in brain tissue or the detection of anti-measles antibodies in the CSF.

Six of the patients had normal EEGs when first examined, an average of 6 months after the onset of illness. This group did not differ from those with abnormal EEGs in any important detail including age, sex, measles antibody titer, severity or duration of illness or the length of survival. A11 of the EEGs eventually became abnormal, 4 with the classical suppression burst pattern considered diagnostic for SSPE. At the time of the nomal tracing, one patient had well developed myoclonus.

These findings indicate that a nomal EEG is common in SSPE even when the clinical disease is moderately advanced. This re-emphasizes the diagnostic importance of CSF measles antibodies when other studies are normal.

COUNTER IMMUNELECTROPHORESIS IN HEMOPHILUS INFLUENZAE TYPE B EPIGLOTTITIS AND PERICARDITIS. Edward W.P. Smith and David L. Ingram, Dept. of Ped., Yale Univ. Sch. of Med., Yale-New Haven Hosp., New Haven, and Dept. of Ped., Harvard Med. Sch., Children's Hosp. Med. Ctr., Boston (Intr. by H. A. Pearson).

Counterimmunelectrophoresis (CIE) was used to detect polyribophosphate (PRP), the capsular polysaccharide antigen of Hemophilus influenzae type b (H.flu.b), in sera of patients with H.flu.b epiglottitis and sera and pericardial fluids of patients with H.flu.b pericarditis.

CIE was performed for 30 mins. at 30 milliamps using $\left(\mathrm{NH}_{4}\right)_{2}$ $\mathrm{SO}_{4}$ precipitated rabbit antisera and Hyland agar gel plates. The sera of 7 patients with H. $f 1$ u.b epiglottitis were tested prior to IV Ampicillin therapy. Immunoprecipitin bands became visible in 3 specimens after cooling for $30 \mathrm{mins}$. and in a fourth after cooling for $10 \mathrm{hrs}$. Three sera contained $5 \mathrm{ng}$ of PRP per ml, while the fourth contained between 2.5 and $5 \mathrm{ng}$ of PRP per $\mathrm{ml}$, a quantity which represents the lower limits of sensitivity for this technique. The brief course of epiglottitis prior to therapy may explain the small amount of PRP produced.

In contrast, pericardial fluids and sera of 3 patients with H.flu.b pericarditis were markedly positive. Two pericardial fluids were quantitated. The first contained $5.85 \times 10^{5} \mathrm{ng}$ of PRP per $\mathrm{ml}$ and the second contained $19 \times 10^{5} \mathrm{ng}$ of PRP per ml. The pericardial sac may function as a depot for large amounts of antigen.

\section{ABNORMAL COLONIZATION AND INFECTION IN NEONATES} Katherine Sprunt, Grace Leidy and Winifred Redman, College of Physicians and Surgeons, Columbia University, Babies Hosp, Dept. Ped., N.Y.C.

The incidence of infection and its relationship to bacterial colonization of the pharynx of infants in a neonatal ICU has been investigated. Pharyngeal bacterial flora were frequently monitored on a semi-quantitive basis in 62 infants with RDS and 70 concurrent broadly marched controls. All infections occurred in infants with high abnormal colonization and were due to the type of bacterium producing the high colonization. Early high abnormal colonization occurred more frequently in RDS infants $(42 \%)$ than in controls $(27 \%)$; this high incidence was independent of antibiotic treatment. 5 of 9 abnormally colonized RDS infants without therapy had sepsis compared to only 1 of 5 control infants (urinary tract infection). Staphylococcus epidermidis and Gram negative enteric bacilli were the most frequent causes of high colonization; most infections were due to the enteric bacilli. Infection rates were similar in the two groups receiving antibiotics (RDS $4 / 41$, controls $3 / 50$ ) but differed when no antibiotics were given (RDS 6/21, controls $1 / 20$ ). We recommend that all ICU infants, particularly those with RDS, be followed closely with frequent throat cultures to determine those with added risk of infection. Abnormally colonized infants should be treated on minimal indication as directed by the antibiotic sensitivity of the colonizing organism.
BACTERIA AND PHOTOTHERAPY, J.S.Storer,L.T.Gutman,G.W.Brumley (Intro.S.L.Katz). Dept.Ped. Duke Univ. Med.Ctr., Durham, N.C.

To identify alterations in multiplication and antimicrobial sensitivity patterns, Staphylococcus aureus ( S. a. ), Escherichia coli (E.c.) and Streptococcus pyogenes (S.p.) were exposed to quantities of blue light $(400-500 \mathrm{~nm})$ comparable to those used in phototherapy of neonatal hyperbilirubinemia.

Multiplication of $\underline{\text { S.p. }}$. was significantly decreased by photoirradiation:1)delivered for $8 \mathrm{hrs}$. or longer with a fixed radiant flux of $28 \mu \mathrm{w} / \mathrm{cm}^{2}$ (measured at $455 \mathrm{~nm}$ ) (Tab.A) and 2) with radiant flux of $14 \mu \mathrm{w} / \mathrm{cm}^{2}$ or more for a fixed time of 48 hours (Tab.B). Abnormal bacterial appearance on Gram stain, "fried egg" colony appearance and transferability of variant colonies on solid medium indicated that photoirradiation had induced cell wall defective variants of S.p. after one hour at $28 \mu \mathrm{w} / \mathrm{cm}^{2}$.

S.a.e, photoirradiated at $2 \overline{8} \mu \mathrm{w} / \mathrm{cm}^{2}$ for 48 hours, exhibited increased sensitivity to kanamycin $(p<.1)$ as compared to controls. Multiplication of $\underline{S}$. $\underline{\text { a }}$. was not affected. Photoirradiation of E.c. had no effect. Morphology of photoirradiated $\underline{S} . \underline{a}$. and E.c. was normal.

These results suggest that blue light in phototherapeutic amounts may affect bacterial cell wall, as manifested by decreased rates of multiplication, transferable abnormal cellular morphology, and increased sensitivity to kanamycin.

A. Irradiation at $28 \mathrm{uw} / \mathrm{cm}^{2} \quad$ B. Irradiation for 48 hours

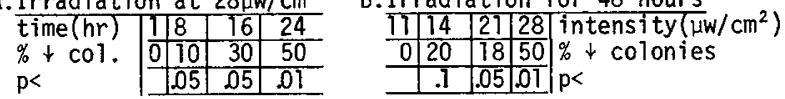

EPIDEMIC OF KANAMYCTN RESISTANT SERRATIA MARCESCENS SEPSIS IN A NEWBORN INTENSIVE CARE UNIT. M. Akram Tamer, Ellen Monkus, and George Counts. (Intr. by William W. Cleveland). Dept. of Ped, and Path., Univ. of Miami Sch. Med., Miami, Fla. During a period of 18 months, 15 cases of Serratia septicemia were identified in the Neonatal ICU of a large county hospital including two outbreaks of 5 and 4 cases each.

$\frac{\text { Weight }}{2,500 \mathrm{gm}} \quad \frac{\text { Surviva1/Patient Number }}{5 / 13} \frac{\text { Mortality }}{61 \%} \frac{\text { Age at Onset }}{1 \text { to } 15 \text { days }}$

$\begin{array}{rlrr}2,500 \mathrm{gm} & 5 / 13 & 61 \% & 1 \text { to } 15 \text { days } \\ 2,500 \mathrm{gm} & 1 / 2 & & 8 \text { days }\end{array}$

Both term infants were postoperative patients (TE-fistula).

An epidemiologic survey of the Neonatal ICU ( 8 beds) and

the adjacent premature nurseries ( 35 beds) revealed:

Equipment: $5 / 230$ cultures grew Serratia

Personne1: 2/67 ( 2 nurse's hands)

Infants : 9/238 ( $5 \mathrm{NP}, 3$ rectal, 1

Control measures included strict hand washing with change

from hexachlorophene to a povidone-iodine preparation, elimination of water in isolettes, and rinsing of hands, isolettes and other equipment with $2 \%$ acetic acid. Gentamycin replaced kanamycin in accordance with the sensitivities. Two premature infants with meningitis survived after treatment with systemic and intrathecal gentamycin.

In a nursery epidemic of sepsis and meningitis due to Serratia marcescens, significant morbidity and mortality was seen in premature and ill neonates. This emphasizes the importance of considering any microorganism as a potential devastating pathogen in susceptible populations.

DISEASE PREVENTION BY MENINGOCOCCAL SEROGROUP C POLYSACCHARIDE VACCINE IN PRESCHOOL CHILDREN: RESULTS AFTER ELEVEN MONTHS IN SAO PAULO, BRAZIL. Augusto de E. Taunay, Paulo A. Galvao, Jose S. de Morais, Emil C. Gotschlich, Roger A. Feldman. Instituto Adolfo Lutz, Sao Paulo, Brazil; Hospital Emilio Ribas, Sao Paulo; Regional Health Department, Greater Sao Paulo; Rockefeller University, New York; Center for Disease Contro1, Atlanta, Georgia.

During an outbreak of serogroup $C$ sulfonamide-resistant Neisseria meningitidis in the city of Sao Paulo, Brazil,

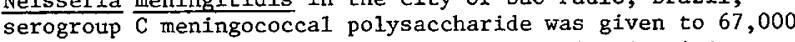
children between 6 and 35 months of age, using jet injector guns and a 50 microgram dose without any preservative. An equivalent number of children received a diphtheria-tetanus toxoid injection. Allocations of children to the vaccine or control groups were made by the use of random number tables at 24 vaccine centers throughout the city during the period December $12-22,1972$.

Serologic studies of 133 children receiving the vaccine or the control materials were completed using a radioimmunoassay technique and indicated that the program of vaccination was effective in initiating serologic response.

After 11 months of follow-up, 32 cases of culture- or counterimmunoelectrophoresis-proven serogroup $C$ meningococcal disease have occurred in children who took part in the vaccine trial. Although there is no indication that the vaccine was effective in preventing disease in the children from 6 to 23 months of age, those between 24 and 35 months of age appeared to be protected. The trial is continuing. 